\title{
The Influence of Radiation on Confinement Properties of Nuclear Waste Glasses
}

\author{
Viktor I. Malkovsky, ${ }^{1}$ Sergey V. Yudintsev, ${ }^{1}$ Michael I. Ojovan $\mathbb{D}^{1},{ }^{1,2}$ and Vladislav A. Petrov ${ }^{1}$ \\ ${ }^{1}$ Institute of Geology of Ore Deposits, Petrography, Mineralogy and Geochemistry, Moscow 119017, Russia \\ ${ }^{2}$ Department of Materials, Imperial College London, London SW7 2AZ, UK
}

Correspondence should be addressed to Michael I. Ojovan; m.ojovan@sheffield.ac.uk

Received 25 May 2020; Accepted 16 July 2020; Published 1 August 2020

Academic Editor: Jariah Mohamad Juoi

Copyright (c) 2020 Viktor I. Malkovsky et al. This is an open access article distributed under the Creative Commons Attribution License, which permits unrestricted use, distribution, and reproduction in any medium, provided the original work is properly cited.

\begin{abstract}
Self-irradiation can affect durability of glasses used to immobilize high-level nuclear waste (HLW). The stability of glasses can also be indirectly affected by the radiolytic changes in contact water leading to decrease in its $\mathrm{pH}$ although this is unlikely to occur for disposal systems where the interaction of groundwater with glass is delayed to times when radiation dose rates are decreased to levels insignificant to cause such effects. Besides, interaction of the water influenced by radiation with other repository protective elements (container and bentonite) will suppress the radiolytic changes. Literature analysis shows practical absence or very weak effect of self-irradiation on structure and characteristics of borosilicate glasses with typical content of nuclear waste. Data for aluminophosphate glass used in Russia have showed that, after $\gamma$-irradiation with a dose of $6.2 \cdot 10^{7} \mathrm{~Gy}$, the leaching rates of elements were decreased approximately twice relatively to pristine samples.
\end{abstract}

\section{Introduction}

Safe and effective management of nuclear waste is crucial to ensure the sustainable utilization of nuclear energy [1]. Radioactive waste, which is a toxic by-product from nuclear fuel cycle, should be immobilized into a robust form (matrix) before its temporary storage and consequent disposal [2]. Durable wasteform materials used for this purpose provide the most important barrier contributing to overall performance of storage and disposal systems [3]. Currently only vitreous matrices (B-Si and $\mathrm{Na}-\mathrm{Al}-\mathrm{P}$ glasses) are applied throughout the world for high-level waste (HLW) immobilization [2-4]. Alkali-borosilicate (ABS) glasses are used for vitrification of HLW except Russia that uses sodiumaluminum-phosphate (NAP) glasses (Table 1).

One of the actual tasks is to analyse the effects caused by self-irradiation of nuclear waste glass properties. Self-irradiation occurs in glasses hosting nuclear waste and causes complex radiation-induced changes. The role of self-irradiation in the behavior of nuclear waste glasses is not understood fully, and experimental evidence is controversial ranging from insignificant to a notable impact [17-19]. For example, formation of structural defects due to irradiation can enhance diffusion of cations in glasses as well as leaching rates. On the contrary, radiation-induced annealing of glass normally reduces leaching rates $[5,20]$.

Vitrified HLW is placed in hermetically sealed containers pending disposal in geological disposal facilities (GDFs) at a depth of $0.5-1 \mathrm{~km}$. In hundred years after completion of operation, the GDF with vitrified HLW will be eventually filled with groundwater [6]. Over time, the containers will corrode, and underground water will contact vitrified HLW. The composition of HLW immobilizing glasses is the result of a compromise between desire to increase capacity in relation to hazardous radionuclides, manufacturing ability, and reliability of radionuclides confinement [6-12]. Most industrial HLW vitrification plants in the world preferred borosilicate glass. Borosilicate glasses along with aluminum-phosphate glass are considered as a promising material for vitrification of HLW in Russia. The advantages of aluminum-phosphate glasses are due to their lower melting temperature, one-stage technology of 
TABLE 1: HLW industrial immobilization (vitrification) plants [2, 4-16].

\begin{tabular}{|c|c|c|}
\hline Country & Facility & Type of glass: composition in wt.\% \\
\hline Russia & EP500 PA “Mayak" & NAP: $53.3 \mathrm{P}_{2} \mathrm{O}_{5} \cdot 15.8 \mathrm{Al}_{2} \mathrm{O}_{3} \cdot 1.6 \mathrm{Fe}_{2} \mathrm{O}_{3} \cdot 23.5 \mathrm{Na}_{2} \mathrm{O} \cdot 5.8$ miscellaneous ${ }^{1}$ \\
\hline Belgium & Pamela & NAP: $70.7 \mathrm{P}_{2} \mathrm{O}_{5} \cdot 7.1 \mathrm{Al}_{2} \mathrm{O}_{3} \cdot 22.2 \mathrm{Fe}_{2} \mathrm{O}_{3}$ \\
\hline Belgium & Pamela & ABS: $52.7 \mathrm{SiO}_{2} \cdot 13.2 \mathrm{~B}_{2} \mathrm{O}_{3} \cdot 2.7 \mathrm{Al}_{2} \mathrm{O}_{3} \cdot 4.6 \mathrm{CaO} \cdot 2.2 \mathrm{MgO} \cdot 5.9 \mathrm{Na}_{2} \mathrm{O} \cdot 18.7$ miscellaneous \\
\hline France & AVM Marcoule & ABS: $46.6 \mathrm{SiO}_{2} \cdot 14.2 \mathrm{~B}_{2} \mathrm{O}_{3} \cdot 5.0 \mathrm{Al}_{2} \mathrm{O}_{3} \cdot 2.9 \mathrm{Fe}_{2} \mathrm{O}_{3} \cdot 4.1 \mathrm{CaO} \cdot 10.0 \mathrm{Na}_{2} \mathrm{O} \cdot 17.2$ miscellaneous \\
\hline France & AVH R7/T7 La Hague & ABS: $54.9 \mathrm{SiO}_{2} \cdot 16.9 \mathrm{~B}_{2} \mathrm{O}_{3} \cdot 5.9 \mathrm{Al}_{2} \mathrm{O}_{3} \cdot 4.9 \mathrm{CaO} \cdot 11.9 \mathrm{Na}_{2} \mathrm{O} \cdot 5.5$ miscellaneous \\
\hline Germany & Karlsruhe & ABS: $60.0 \mathrm{SiO}_{2} \cdot 17.6 \mathrm{~B}_{2} \mathrm{O}_{3} \cdot 3.1 \mathrm{Al}_{2} \mathrm{O}_{3} \cdot 5.3 \mathrm{CaO} \cdot 7.1 \mathrm{Na}_{2} \mathrm{O} \cdot 6.9$ miscellaneous \\
\hline UK & WVP Sellafield & ABS: $47.2 \mathrm{SiO}_{2} \cdot 16.9 \mathrm{~B}_{2} \mathrm{O}_{3} \cdot 4.8 \mathrm{Al}_{2} \mathrm{O}_{3} \cdot 5.3 \mathrm{MgO} \cdot 8.4 \mathrm{Na}_{2} \mathrm{O} \cdot 17.4$ miscellaneous \\
\hline US & DWPF Savannah River & ABS: $49.8 \mathrm{SiO}_{2} \cdot 8.0 \mathrm{~B}_{2} \mathrm{O}_{3} \cdot 4.0 \mathrm{Al}_{2} \mathrm{O}_{3} \cdot 1.0 \mathrm{CaO} \cdot 1.4 \mathrm{MgO} \cdot 8.7 \mathrm{Na}_{2} \mathrm{O} \cdot 27.1$ miscellaneous \\
\hline US & WVDP West Valley & ABS: $45.8 \mathrm{SiO}_{2} \cdot 8.4 \mathrm{~B}_{2} \mathrm{O}_{3} \cdot 6.1 \mathrm{Al}_{2} \mathrm{O}_{3} \cdot 11.4 \mathrm{Fe}_{2} \mathrm{O}_{3} \cdot 1.4 \mathrm{MgO} \cdot 9.1 \mathrm{Na}_{2} \mathrm{O} \cdot 17.8$ miscellaneous \\
\hline US & WTP Hanford (under construction) & ABS: $50.0 \mathrm{SiO}_{2} \cdot 20.0 \mathrm{~B}_{2} \mathrm{O}_{3} \cdot 5.0 \mathrm{Al}_{2} \mathrm{O}_{3} \cdot 25.0 \mathrm{Na}_{2} \mathrm{O}$ \\
\hline Japan & Tokai Vitrification Facility & ABS: $46.7 \mathrm{SiO}_{2} \cdot 14.3 \mathrm{~B}_{2} \mathrm{O}_{3} \cdot 5.0 \mathrm{Al}_{2} \mathrm{O}_{3} \cdot 3.0 \mathrm{CaO} \cdot 9.6 \mathrm{Na}_{2} \mathrm{O} \cdot 21.4$ miscellaneous \\
\hline India & WIP Trombay & ABS: $30.0 \mathrm{SiO}_{2} \cdot 20.0 \mathrm{~B}_{2} \mathrm{O}_{3} \cdot 25.0 \mathrm{PbO} \cdot 5.0 \mathrm{Na}_{2} \mathrm{O} \cdot 20.0$ miscellaneous \\
\hline India & AVS Tarapur & ABS: $34.1 \mathrm{SiO}_{2} \cdot 6.4 \mathrm{~B}_{2} \mathrm{O}_{3} \cdot 6.2 \mathrm{TiO}_{2} \cdot 0.2 \mathrm{Na}_{2} \mathrm{O} \cdot 9.3 \mathrm{MnO} \cdot 43.8$ miscellaneous \\
\hline
\end{tabular}

${ }^{1}$ Miscellaneous includes waste oxides.

production from the liquid state, and therefore, a more economical technology for its manufacture. Also, the glass has a high solubility of sulphates, chromates, and molybdates $[7,13]$. However, it also possesses essential drawbacks: a higher leaching rate in water on increase in temperature compared to borosilicate glasses [21] and the presence of chain catalytic crystallization in air at temperatures of $250-300^{\circ} \mathrm{C}$ in the presence of unsaturated water steam [22]. In borosilicate glasses, steam hydration at such temperatures produces only thin outer surface layer with thickness from $10 \mu \mathrm{m}$ [23] to several millimetres for a long time [24], whereas sample of aluminum-phosphate glass cubic in shape and edge equal to $1 \mathrm{~cm}$ was crystallized during a day at $300^{\circ} \mathrm{C}$ and $66 \%$ air humidity.

The source of intensive radiation in HLW is decay of waste radionuclides. The thermal energy released during this process leads to a significant increase in the temperature of vitrified HLW located in the storage facility and final repository. According to the estimates [17], temperature in the Yucca Mountain disposal facility can exceed $250^{\circ} \mathrm{C}$. The radiation can also affect the properties of vitrified HLW and change its stability when interacting with groundwater. This interaction can lead to an increase in radionuclide release from glass to groundwater and ultimately reduce the safety of the disposal facility. This paper discusses the impact of self-irradiation on properties and reliability of nuclear waste glasses used as HLW matrices based on an analysis of published data.

\section{Sources of Self-Irradiation in Vitrified HLW}

A wide range of immobilized radionuclides causes various sources of self-irradiation of vitrified HLW, including $\alpha$-decay of minor actinides, $\beta$-decay of fission products, $\gamma$-radiation resulting from the decay of radionuclides, and $(n, \alpha)$ nuclear reactions [5]. Dynamics of $\alpha$ - and $\beta$-self-irradiation of vitrified HLW is presented in Figure 1.

$\alpha$-Decay of minor actinides especially for $\mathrm{Np}, \mathrm{Am}$, and Cm takes place in HLW. As a result, two charged particles are formed: a helium ion with an energy of the order of $4-6 \mathrm{MeV}$ and the so-called heavy recoil nucleus, i.e., the nucleus of a mother radionuclide that has lost an $\alpha$-particle

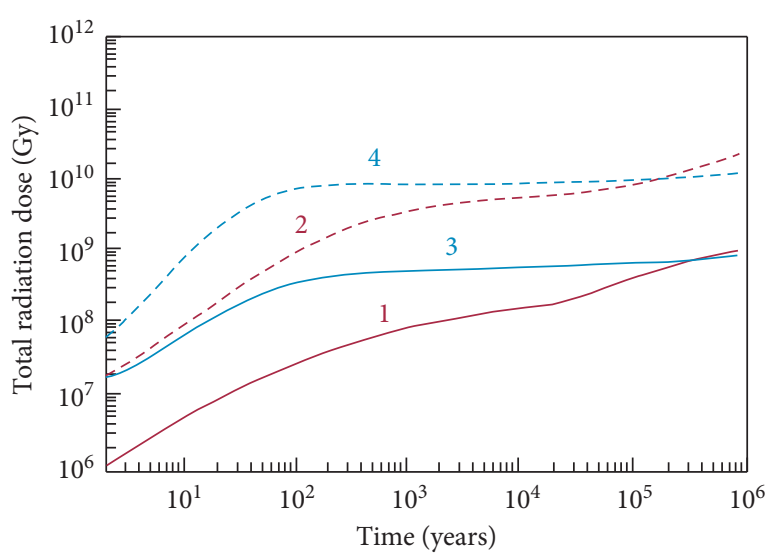

Figure 1: Absorbed dose (Gy) of HLW according to [17]. 1, $\alpha$-radiation of defense HLW; $2, \alpha$-radiation of commercial HLW; 3 , $\beta$-radiation of defense HLW; $4, \beta$-radiation in commercial HLW.

and received an energy of the order of $0.1 \mathrm{MeV}$ due to the law of conservation of momentum (Table 2).

The difference between defense and commercial HLW is due to the depth (degree) of burnup of spent nuclear fuel (SNF) extracted from reactors. In the case of defense use, the burnup is an order of magnitude smaller compared with commercial use so that there is no large production of even isotopes of plutonium such as ${ }^{240} \mathrm{Pu}$ in the fuel, but rather accumulation of fissile radionuclides such as ${ }^{239} \mathrm{Pu}$ to create atomic bombs. As a result, commercial SNF has a different composition-a much larger content of fission products and minor actinides, which is why the SNF and the HLW resulting from its reprocessing has a much higher activity, which is clearly seen in Figure 1.

In addition, $\alpha$-decay is accompanied by $\gamma$-radiation caused by deexcitations of radionuclides ( $\gamma$-transitions). Over a million years, the integral density of $\alpha$-decays will amount $10^{19}$ events per gram in vitrified defense HLW $[6,17]$ and $2 \times 10^{20}$ events/g in the commercial vitrified HLW, resulting from reprocessing of spent fuel of nuclear power plants (Figure 2).

Collisions of charged particles with atoms of elements of borosilicate glass lead to atomic displacements and can cause 
TABLE 2: Self-irradiation types in HLW borosilicate glass matrices, after $[4,6,17]$.

\begin{tabular}{lcccc}
\hline Source (type) of radiation & Range of defects in solid & Dose after $10^{4}$ years, Gy & Dose after $10^{6}$ years, Gy & Displacements per decay \\
\hline $4-6 \mathrm{MeV} \alpha$-particles & $\sim 20 \mu \mathrm{m}$ & $3 \cdot 10^{9}$ & $10^{10}$ & $\sim 200$ \\
$\sim 0.1 \mathrm{MeV}$ recoil nuclei & $\sim 30 \mathrm{~nm}$ & $\sim 6 \cdot 10^{7}$ & $\sim 3 \cdot 10^{9}$ & $\sim 2000$ \\
$\beta$-Particles & $\sim \mathrm{mm}$ & $\sim 3 \cdot 10^{9}$ & $\sim 4 \cdot 10^{9}$ & 1 \\
$\gamma$-Irradiation & $\sim 2 \mathrm{~cm}$ & $\sim 2 \cdot 10^{9}$ & $\sim 2 \cdot 10^{9}$ & $<1$ \\
$(n, \alpha)$ nuclear reactions & $\sim 1 \mathrm{~m}$ & $\sim 2 \cdot 10^{2}$ & $\sim 3 \cdot 10^{3}$ & $\sim 200-2000$ \\
\hline
\end{tabular}

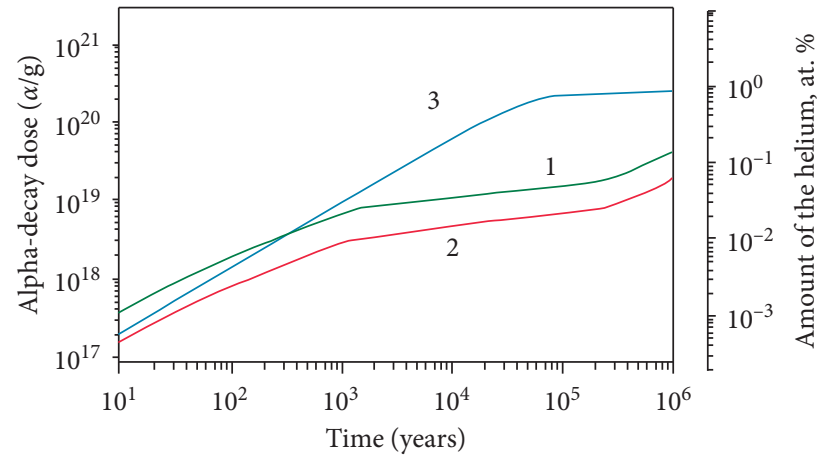

Figure 2: Dynamics of cumulative $\alpha$-decay events per gram and helium accumulation in the vitrified HLW (Table 3 ) due to $\alpha$-irradiation: 1, defense HLW; 2, civil HLW with a low content of minor actinides; 3 , HLW with a high content of minor actinides.

changes in glass structure. The $\alpha$-particle receives more energy than the recoil nucleus, but the number of atomic displacements due to the recoil nuclei significantly exceeds the number of displacements from the $\alpha$-particle, forming cascades of displacements. So structural changes in vitreous radioactive wasteforms are largely due to cascades of atomic displacements of glass structural elements generated by recoil nuclei than collisions with $\alpha$-particles. When stopping, the charge of $\alpha$-particles is neutralized, and $\alpha$-particles are transformed into helium atoms. An increase in the helium content in the sample and partial violations of glass structure can thus change properties of borosilicate glass, its density and stability when interacting with hot water.

$\beta$-Decay of fission radionuclides, mainly of ${ }^{137} \mathrm{Cs}$ and ${ }^{90} \mathrm{Sr}$, takes place as follows:

$$
{ }^{137} \mathrm{Cs}^{+} \underset{1}{\longrightarrow}{ }^{137 m} \mathrm{Ba}^{2+}+\beta^{-} \underset{2}{\longrightarrow}{ }^{137} \mathrm{Ba}^{2+}+\gamma
$$

The half-life in the first reaction is about 30 years and the second 2.6 minutes. The disintegration of ${ }^{90} \mathrm{Sr}$ occurs also as a two-stage reaction:

$$
{ }^{90} \mathrm{Sr}^{2+} \underset{1}{\longrightarrow}{ }^{90} \mathrm{Y}^{3+}+\beta^{-} \underset{2}{\longrightarrow}{ }^{90} \mathrm{Zr}^{4+}+\beta^{-}
$$

The half-life in the reaction of the first stage is 28.8 years and the second 64 hours. At the end of the two-stage fission of ${ }^{137} \mathrm{Cs}$ and ${ }^{90} \mathrm{Sr}$, stable isotopes $\mathrm{Ba}$ and $\mathrm{Zr}$ are formed. The energy of $\beta$-particles generated during the decay lies in the range from several hundred $\mathrm{keV}$ to $1 \mathrm{MeV}$. Due to the relatively short half-lives of ${ }^{137} \mathrm{Cs}$ and ${ }^{90} \mathrm{Sr}$, half of the dose of $\beta$-radiation is obtained by vitrified HLW during the first $10-30$ years of storage $[5,17]$. The total dose of $\beta$-radiation received by vitrified HLW for 10 thousand years is $3 \times 10^{9} \mathrm{~Gy}$
(Table 2). The effect of $\beta$-radiation is associated, firstly, with collisions of electrons with the atoms of elements of vitreous matrix and breaking of bonds between them. At the second, $\mathrm{Ba}^{2+}$ and $\mathrm{Zr}^{4+}$ forming instead of Cs and Sr have radii of $20 \%$ less than that of $\mathrm{Cs}^{+}\left(\mathrm{Ba}^{2+}\right)$ and $29 \%$ less than that of $\mathrm{Sr}^{2+}$ $\left(\mathrm{Zr}^{4+}\right)$. Both these factors can affect properties and durability of borosilicate glasses in underground waters. The processes of $\alpha$ - and $\beta$-decay are accompanied by intense $\gamma$-radiation. In addition, $\gamma$-radiation is the result of electronic collisions at low braking energies. The absorption of gamma rays by electrons of glass structural elements can lead to breaking of chemical bonds, including that of oxygen atoms, appearance of unbound ions, and formation of free oxygen in glass. The dose of $\gamma$-radiation, in which ABS glass with HLW absorbed in 10,000 years, will be $2 \times 10^{9} \mathrm{~Gy}$.

There is a self-irradiation source characteristic to nuclear borosilicate glasses only-so-called $(n, \alpha)$ reaction, which occurs as follows. Neutrons formed in the decay reactions (spontaneous fission of minor actinides), as a result of collisions with other atoms, gradually lose their kinetic energy and become thermal; i.e., their energy is reduced to the level of gas molecules under normal conditions. Selfirradiation of borosilicate glasses with thermal neutrons leads to an $(n, \alpha)$ reaction:

$$
{ }^{10} \mathrm{~B}+n \longrightarrow \alpha+{ }^{7} \mathrm{Li}
$$

The decay energy is divided unevenly between products of $(n, \alpha)$ reaction: the energy of $\alpha$ particle is approximately equal to $1.48 \mathrm{MeV}$, and the energy of lithium ion is $0.48 \mathrm{MeV}$. After a relatively rapid deceleration, the $\alpha$-particle produces a helium atom. HLW contains a low amount of minor actinides that can serve as a source of neutrons due to spontaneous fission. Therefore, in comparison with three discussed above sources of self-irradiation, the reaction ( $n$, $\alpha$ ) plays a subordinate role.

\section{Research Methods}

An important problem that arises at estimation of long-term safety of HLW disposal is the need to study processes that occur for many thousands of years, both their initial and final stages being equally important. The complexity of these processes and special requirements for reliability of their analysis do not always allow the development of theoretical models with high accuracy, and direct experimental research of processes on such a timescale is unrealistic. Therefore, an important task is to develop the experimental techniques that allow, within an acceptable period of time, to determine the main characteristics of events under study throughout its entire duration. The main irradiation methods including 
accelerated ones are shown schematically in Figure 3 [2] and briefly discussed below.

3.1. Doping of Glass with Radionuclides. Intensively emitted radionuclides allow investigating the effect of irradiation on durability of glasses. Radionuclides with short half-lives are used to reduce the time required to accumulate a given total radiation dose. To study the effect of $\alpha$-decay, typically shorter-lived radionuclides such as ${ }^{244} \mathrm{Cm}$ and ${ }^{238} \mathrm{Pu}$ are used $[4,6,7,25,26]$. An undoubted advantage of this method is its ability to evaluate the uniform effect of radiation on the bulk sample volume. A feature of this method is the need to work with highly radioactive samples. The main disadvantage is the probability of artifacts caused by an excessively high level of radiation exposure. To analyse this possibility, experiments are performed on glasses containing different amounts of radionuclides, and the results are compared $[4,5]$. It can be noted that the effect of increased $\alpha$-radiation intensity on the density of borosilicate glass is rather small (Figure 4).

We note that, in France, the bulk of SNF was reprocessed and the largest amount of vitrified HLW was vitrified. This is why French glasses (Figure 4 and Table 3 ) are the most studied and can be considered as a reference for comparison.

It has been recently revealed that highly alpha-radioactive borosilicate glass doped with 0.5 wt.\% of ${ }^{238} \mathrm{PuO}_{2}$ in aqueous solutions behaved essentially differently in comparison with nonradioactive glass of similar chemical composition due to effects of radiolysis combined with radiation damage that considerably accelerated glass alteration under saturated conditions and led to formation of a nondurable gel layer on glass [26].

3.2. Study of Real Vitrified HLW. This method is not quite suitable for studying the effect of $\alpha$-radiation, the source of which is long-lived actinides. However, in this case, a long observation period is not required because the glass receives half of the total dose of $\beta$ - and $\gamma$-radiation already within the first 10-30 years after being placed in storage or disposal sites. To study the effect of $\beta$ - and $\gamma$-radiation, numerous investigations were performed on vitreous waste forms since 1970 s, both with nonradioactive and radioactive imitators buried in real geologic environment such as limestones and clays $[27,28]$. Duration of the field tests was up to 30 years, and the glasses studied contained ${ }^{134} \mathrm{Cs},{ }^{90} \mathrm{Sr}$, and ${ }^{239} \mathrm{Pu}$. The total radioactivity of the sample reached $500 \mathrm{MBq} / \mathrm{g}$ by sum of $\beta$ - and $\gamma$-emitted nuclides.

3.3. Method of External Exposure. Borosilicate glass samples are bombarded with helium ions (to simulate $\alpha$ radiation and $(n, \alpha)$ reactions), neutrons (in research reactors), electrons (including using SEM and TEM), and $\gamma$-radiation (from sources containing ${ }^{137} \mathrm{Cs}$ and ${ }^{60} \mathrm{Co}$ isotopes). To more accurately simulate real processes of $\alpha$-decay in borosilicate glasses, the samples are simultaneously bombarded with helium ions and substantially heavier elements. Significant doses of $\alpha$-irradiation can be reached under conditions of necessary cooling of samples during bombardment. This method is also quite effective for providing significant doses of $\beta$-radiation in a short time. When using SEM and TEM, the total dose of $1 \times 10^{9} \mathrm{~Gy}$ is accumulated in $1 \mathrm{~min}$, while the total dose of $\beta$-irradiation for $10^{6}$ years is $4 \times 10^{9} \mathrm{~Gy}$ (see Table 2). It should only be borne in mind that low-energy electrons of SEM are inhibited in the sample and create a negative charge in it, which accumulates over time and begins to repel new electrons.

Method of $\gamma$-irradiation was used in many works $[4-7,13,17,18,29]$. However, the total dose was of the order of several MGy, which corresponds to a storage time of glass of about 1 year. By 2017, in only one work [29], the total dose of $\gamma$-radiation has reached $0.85 \times 10^{9} \mathrm{~Gy}$, which corresponds to twenty years storage of real HLW. To study the effect of radiation on properties of glasses, neutron irradiation of samples was also used [17]. Fast neutrons lead to multiple displacements of the atoms as a result of collisions with structural elements of borosilicate glass; however, this only partially resembles elastic collisions of atoms with $\alpha$-particles and recoil nuclei formed during $\alpha$-decay. Therefore, the results of such experiments have limited application.

Another technique is based on thermal neutron irradiation of glasses containing fissile materials such as ${ }^{235} \mathrm{U}$. After absorption of thermal neutrons, nuclei of these radionuclides decay. As a result of decay, massive fission fragments are formed, which, when they collide with structural elements of glass, create an effect similar to action of recoil nuclei formed on $\alpha$-decay on glass. However, in this way, it is possible to ensure only a relatively small number of decays in the unit mass of the sample, significantly less than the number of $\alpha$-decays in real storage conditions of vitrified HLW (Table 2).

The third technique related to neutron irradiation is used in the experiments with borosilicate glasses irradiated with thermal neutron fluxes and is based on the reaction $(n, \alpha)$. However, as in the previous method, in this way, it is possible to achieve only very limited values of the total dose of the sample irradiated. Due to the above drawbacks, all methods based on use of neutron irradiation of samples are used relatively rarely.

3.4. Molecular Dynamic Simulation. By molecular dynamic (MD) simulation, the accumulation of damage in nuclear waste materials is studied to the displacement per atom (dpa) level corresponding to any necessary time of storage. MD simulation of the displacement cascades associated with the deceleration of heavy atoms with kinetic energy ranging from several hundred $\mathrm{eV}$ to a tenth $\mathrm{keV}$ is used to investigate changes in solids (Figure 2). MD simulations can predict resistance of crystalline materials to amorphization caused by radiation damage. This was demonstrated for several systems [30] where simulations reproduce well-experimental data. For example, collision cascades result in structural damage that is retained in $\mathrm{SiO}_{2}$ and recovers in $\mathrm{Al}_{2} \mathrm{O}_{3}$ consistent with data that show low and high resistances to amorphization of $\mathrm{SiO}_{2}$ and $\mathrm{Al}_{2} \mathrm{O}_{3}$, respectively [31]. $\mathrm{MD}$ simulation was used for 


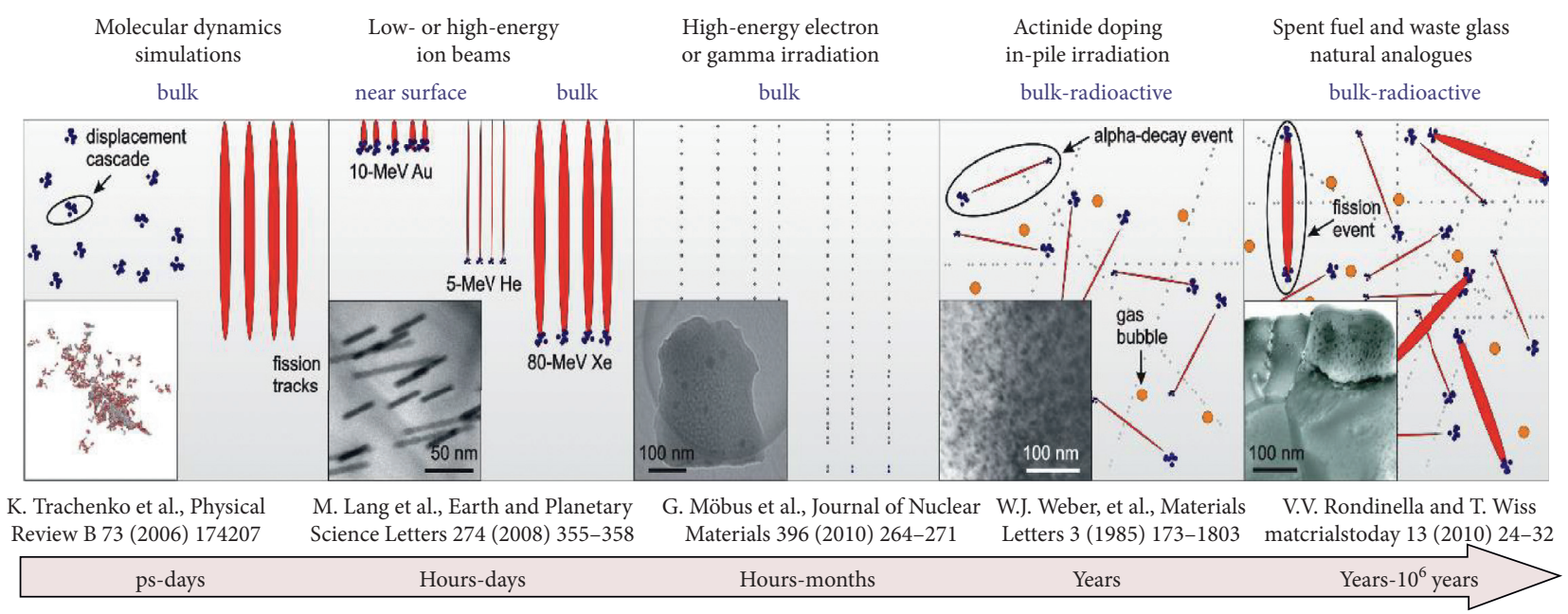

FIGURE 3: Methods to investigate radiation-induced ageing of nuclear materials. Courtesy: Maik Lang, University of Tennessee, US.

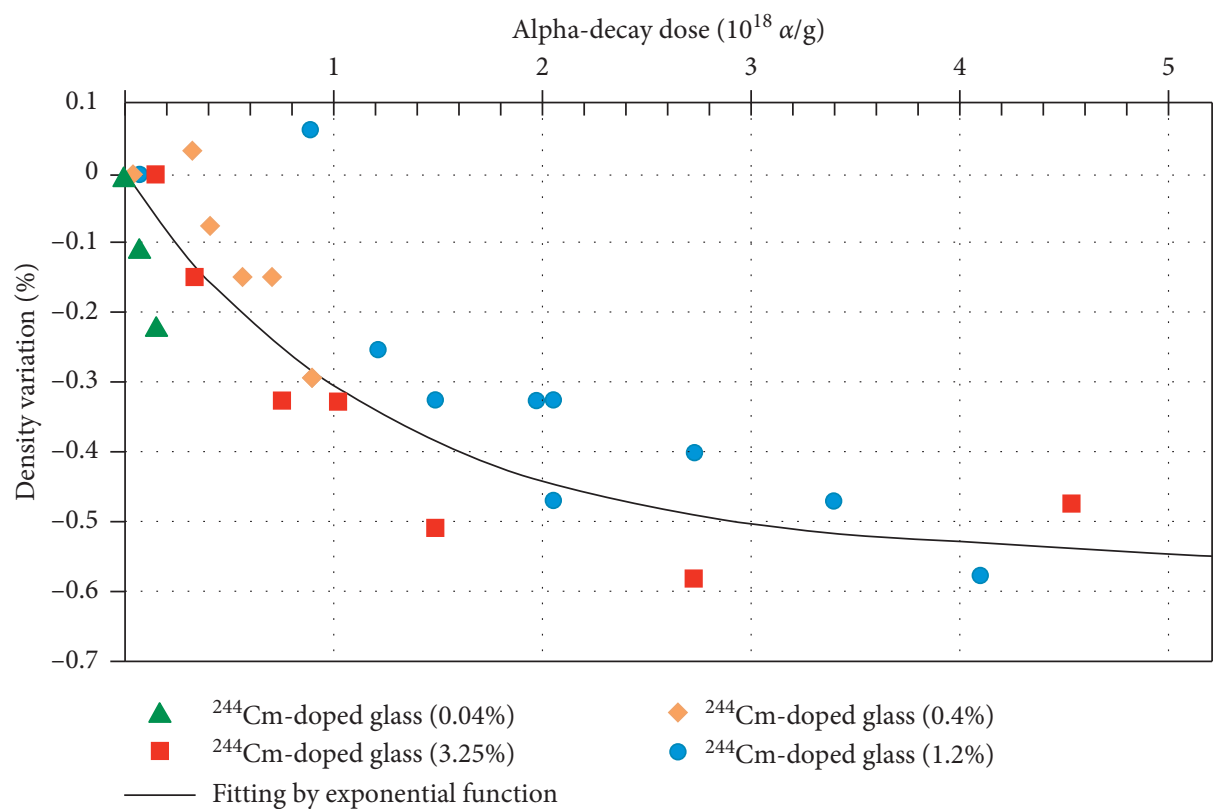

Figure 4: The effect of $\alpha$-radiation caused by the decay of ${ }^{244} \mathrm{Cm}$ on density of borosilicate glass [4, 5]. Composition of the glass is given in Table 3.

TABLE 3: Composition of borosilicate glasses produced by AREVA at La Hague (France).

\begin{tabular}{lccc}
\hline Oxides & Contents, wt.\% & Oxide & Contents, wt.\% \\
\hline $\mathrm{SiO}_{2}$ & $42.4-51.7$ & $\mathrm{Cr}_{2} \mathrm{O}_{3}$ & $<0.6$ \\
$\mathrm{~B}_{2} \mathrm{O}_{3}$ & $12.4-16.5$ & $\mathrm{P}_{2} \mathrm{O}_{5}$ & $<1$ \\
$\mathrm{Al}_{2} \mathrm{O}_{3}$ & $3.6-6.6$ & $\mathrm{Li}_{2} \mathrm{O}$ & $1.6-2.4$ \\
$\mathrm{Na}_{2} \mathrm{O}$ & $8.1-11.0$ & $\mathrm{ZnO}$ & $2.2-2.8$ \\
$\mathrm{CaO}$ & $3.5-4.8$ & Fission products + miscellaneous & $7.5-18.5$ \\
$\mathrm{Fe}_{2} \mathrm{O}_{3}$ & $<4.5$ & Actinide oxides & 0.6 \\
$\mathrm{NiO}$ & $<0.5$ & & \\
\hline
\end{tabular}

glasses generated by rapid quenching to simulate structural changes induced by alpha-decay irradiation [32]. The increase in glass free volume and decrease in the glass polymerization index are the main factors that explain the decrease in hardness of the irradiated glass. These results prove that changes in glass density and mechanical properties under alpha-decay self-irradiation are induced by the $\alpha$-particles and recoil nuclei. 


\section{Effect of $\alpha$-Radiation}

4.1. Changes in Density and Structure of Borosilicate Glass. Figure 5 presents changes in density of borosilicate glasses produced at AREVA, La Hague (France), resulting from $\alpha$-irradiation.

The required total doses corresponding to the irradiation doses of vitrified HLW in storage for $10^{4}$ or $10^{6}$ years were achieved by introducing actinide impurities with short halflives ${ }^{244} \mathrm{Cm}$ [33]. It can be noted that changes in density of glass are rather small and $\alpha$-irradiation can lead to both decrease and increase in its value (Figures 4 and 5). To approximate the dependence of glass density on the absorbed dose of $\alpha$-radiation, the following formula is applied [4]:

$$
\frac{\Delta V}{V}=A[1-\exp (-\mathrm{BD})]
$$

where $\mathrm{V}$ is the specific volume, numerically equal to inverse density, $V=1 / \rho ; \rho$ is the density of glass; $\Delta V$ is the change in the specific volume of glass under $\alpha$-irradiation; $D$ is the total dose of $\alpha$-irradiation absorbed by sample; B is a coefficient; and $A$ is the amplitude of the changes.

According to experimental data, $A= \pm 1.2 \mathrm{rel} . \%$, and this value is achieved at $D=2 \times 10^{18} \alpha / \mathrm{g}$. Changes in the density of borosilicate glass are stabilized at a total dose of $\alpha$-irradiation of more than $4 \times 10^{18} \alpha / g$ [34]. Structural changes in glass upon $\alpha$-irradiation are due to a cascade of displacements caused by recoil nuclei. These changes are similar to changes in the glasses of same composition but without radionuclides at increase in their quenching temperature. Over time, changes in the structure of borosilicate glasses caused by $\alpha$-irradiation are spontaneously compensated. Structural changes under the influence of $\alpha$-radiation are expressed in an increase in the degree of disorder of the glass network. However, these changes and the associated density change are relatively small. This is most probably because the glass structure is inherently disordered by its very nature [5]. It should be noted that, with a slight change in density, the strength characteristics of borosilicate glasses under the influence of $\alpha$-radiation noticeably deteriorated. Thus, Young's modulus decreases by 15-30 rel.\%, and the growth of fracture toughness can reach $50-100$ rel.\% [4, 7, 17]. This decrease in strength properties was explained by decrease in the degree of polymerization under $\alpha$-irradiation as a result of breaking electronic bonds between atoms of structural elements of the glass.

The chemical resistance of vitrified HLW can substantially depend on degree of crystallization of the glass. However, up to a total level of $\alpha$-activity of $10^{19} \alpha / \mathrm{g}$, phase separation in borosilicate glass was not observed. According to Weber et al. [17], this level of activity approximately corresponds to a storage time of HLW equal to $10^{4}$ years. Therefore, we can assume that the effect of $\alpha$ radiation on the separation (crystallization) of phases in borosilicate glass is practically absent.

4.2. Helium Generation in Borosilicate Glass. As a result of collisions with atoms of structural elements of glass, the

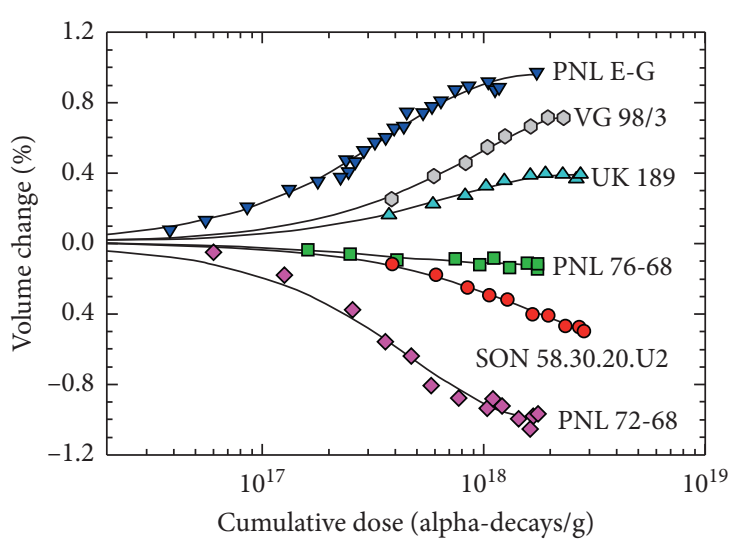

Figure 5: Dependence of the change in the specific volume of glass (volume swelling and compaction) on the dose of $\alpha$-radiation caused by decay of ${ }^{244} \mathrm{Cm}[33]$.

$\alpha$-particle is decelerated and neutralized, and it turns into a helium atom. In [17], it is noted that, at normal temperatures, most of helium formed accumulates (bubbles) in the glass; at $170^{\circ} \mathrm{C}$, from a half to $100 \%$, helium migrates to the glass surface and leaves it. It was previously believed that changes in density of glass under the influence of $\alpha$-radiation are associated precisely with this process of helium generation up to the formation of helium bubbles. Inagaki with coauthors [35] observed formation of helium bubbles with a diameter of $0.15-0.35 \mu \mathrm{m}$ at a total dose of $2.75 \times 10^{25}$ $\alpha$-decays $/ \mathrm{m}^{3}$. The average bubble diameter was $0.23 \mu \mathrm{m}$, and their distribution density in the glass was $10^{17}$ bubbles per $1 \mathrm{~m}^{3}$. According to Inagaki et al. [35], the higher the concentration of helium atoms in glass, the lower the temperatures of gas bubble formation. However, when studying glass of the same composition and values of specific $\alpha$-activity [34], helium bubbles were not observed up to the limit of electron microscope resolution of $10 \mathrm{~nm}$. The differences in the results obtained in these works can be explained by inhomogeneities of glass. This assumption is supported by the fact that the size of gas bubbles decreased with increasing annealing time [35]. Helium resulting from $\alpha$-decay can be in the glass in a dissolved state. According to Gutierrez et al. [36], the limit of dissolved helium in French SON68 borosilicate glass is $2 \times 10^{21}$ atoms $/ \mathrm{cm}^{3}$ (2.5 at.\%). Formation of nano-sized helium bubbles is possible when the concentration of dissolved helium in glass exceeds 3 at.\%, and this is 30 times higher than the helium content in glass after 100,000 years of HLW storage (Figure 2). Thus, taking in account total doses of $\alpha$-radiation corresponding to actual storage times of HLW, the formation of helium bubbles in borosilicate glass due to $\alpha$-decay is unlikely. When analysing the possibility of formation of gas bubbles, one more effect associated with gas generation should be considered, which is a characteristic of changes in borosilicate glass as a result of $\alpha$-decay reactions. The increase in temperature due to $\alpha$-decay shifts the following reaction to the right part:

$$
\mathrm{BO}_{4}=\mathrm{BO}_{3}+\frac{1}{2} \mathrm{O}_{2}(\text { free oxygen })
$$


This leads to a change in the coordination number of boron atoms in the glass structure and to formation of free oxygen gas. Thus, it is possible that, in experiments of Inagaki et al. [35], bubbles are formed not by pure helium but consist of its mixture with oxygen.

Irradiation of borosilicate glasses with heavy ions simulating recoil nuclei leads to more significant changes than irradiation with helium ions ( $\alpha$-particles). Along the track of displacement cascades initiated by the collision of heavy ions with atoms of structure, the local thermodynamic temperature due to collisions of atoms increases significantly up to the melting temperature of glass. When an $\alpha$-particle moves, $99 \%$ of its energy is spent on electron collisions with a braking energy of $0.5 \mathrm{keV}$. This does not lead to a significant increase in temperature, so its local values in this process do not exceed $600^{\circ} \mathrm{C}$, which is less than the glass melting point. However, due to this heating, a local decrease in the disorder of the glass structure occurs. As a result, when glass is bombarded with both heavy and $\mathrm{He}^{2+}$ ions, structural damage to glass by heavy ions (the so-called "ballistic melting" along the tracks of the displacement cascade) is partially restored due to bombardment by helium ions [37].

4.3. Phosphate Glasses. Ion beam irradiation was employed to simulate process of the alpha decay of actinides in iron phosphate nuclear waste glasses [38]. Bismuth and helium ions of different energies have been selected for simulating glass matrix modification owing to radiolysis and ballistic damage due to recoil atoms. After $2 \mathrm{MeV} \mathrm{Bi}$ ion irradiation, it was suggested breaking of dimers $\left(\mathrm{P}_{2} \mathrm{O}_{7}\right)^{4-}$ and forming $\left(\mathrm{PO}_{4}\right)^{3-}$ monomers, which result in depolymerization. The spectroscopy results suggested that depolymerization and breaking of $\mathrm{Fe}-\mathrm{O}-\mathrm{P}$ and $\mathrm{P}-\mathrm{O}-\mathrm{P}$ bonds are attributed to synergetic effect of nuclear and electronic losses. Helium blisters of micron size were seen in the glass sample irradiated at low helium ion with the energy of $30 \mathrm{keV}$. Helium bubble formation observed at high fluence of $2 \times 10^{17}$ ions/ $\mathrm{cm}^{2}$ was attributed due to limited solubility of He atoms in the iron phosphate glass.

\section{Effect of $\beta$-Radiation}

$\beta$-Irradiation of HLW waste glasses produces very few direct atomic displacements from ballistic collisions (atomic displacements from $\gamma$-radiation considered negligible); e.g., atomic displacement rates in HLW glass caused by $\beta$-radiation are two to three orders of magnitude less than that due to alpha decay [33]. Essentially, $\beta$-irradiation on borosilicate glass results in breaking of bonds between elements and changing of tetravalent boron to trivalent [5]. The result of that is the formation of free oxygen and an increase in the disorder of the glass structure. Free oxygen formed as a result of bond breaking can accumulate in bubbles. According to Gin et al. [4], this occurs when the total radiation dose exceeds a certain critical value in the range of $10^{10}-10^{13} \mathrm{~Gy}$, while the critical value depends on the sodium content in glass and temperature: at low $\mathrm{Na}_{2} \mathrm{O}$ contents (4 wt.\%), maximum bubble formation was observed at $325^{\circ} \mathrm{C}$, while at high $\mathrm{Na}_{2} \mathrm{O}$ contents (19-25 wt.\%), it was found at $125-150^{\circ} \mathrm{C}$.

Experimental results indicating changes in structure and density by more than few $\%$ as a result of $\beta$-radiation were obtained on simplified composition of glasses. Meantime, the borosilicate glasses used for real HLW vitrification contain up to 30 different components. Modifier elements in real glasses reduce the effect of $\beta$-radiation on glass properties to an insignificant level [6]. For example, transition metals serve as traps for electrons and holes generated during $\beta$-irradiation of glass, which leads to a decrease in the effect of electron bombardment of the glass until it disappears completely. Electron irradiation of SON68 glasses to a dose of $4.6 \times 10^{9} \mathrm{~Gy}$ which exceeds the expected total $\beta$-dose of vitrified HLW after $10^{6}$ years (see Table 2 ) did not lead to any significant changes in the glass [6].

A major drawback of glass irradiation with low-energy electron beams (keV range) in scanning electron microscopes (SEMs) is the generation of a negative space charge build-up, due to the stopping of primary electrons within the sample. This results in a high field-assisted alkali migration, i.e., accumulation where electrons are implanted, and depletion at the surface and also in a significant local composition modification in the glass. The results obtained must be considered with care, given the material chemistry modification, and should not be considered representative of a nuclear waste ageing scenario. Glass irradiation with an electron beam (ranging in energy from $100 \mathrm{keV}$ to $1 \mathrm{MeV}$ ) in transmission electron microscopes (TEMs) does not suffer from this drawback, as the electrons do not stop within the sample. Oxide glass can undergo structural transformations, including phase separation, oxygen bubble formation, and boron coordination changes. It has been proposed that the intense ionization induced by the high flux of an electron beam causes a decrease in glass viscosity, which favours alkali diffusion and drives phase separation [39]. Moreover, it has been demonstrated that electron stimulated desorption of alkali, oxygen, and silicon atoms or ions through inter- and intraatomic Auger deexcitations is important mechanism that can modify local compositions [40] and could influence glass structural transformation, mainly phase separation within a borosilicate glass due to the preferential depletion in alkali atoms. However, in these tests, the irradiation dose rate was higher by around seven orders of magnitude compared to that characteristic of actual HLW.

\section{Effect of $\gamma$-Radiation}

Numerous irradiations of glasses by $\gamma$-rays have been performed; however, most of the studies have evaluated the response to doses lower than a few MGy, corresponding to less than one year of storage for HLW glasses. Only one study was performed at up to dose of $0.85 \times 10^{9}$ Gy [29]. Similar to electron irradiation, $\gamma$-rays induce the formation of point defects whose nature and amplitude depend on the glass chemical composition. Multivalent cations, like transition metals and rare earths, reduce point defect generation and structural changes in the glass due to the trapping of 
holes and free electrons. $\gamma$-Irradiation, like $\beta$-irradiation, leads to the generation of point defects, consisting of broken bonds between the atoms of structural network of glass and as a result to an increase in disorder and generation of free oxygen. The formation of oxygen bubbles was noted in [41] at a $\gamma$-radiation dose rate of $2.5 \times 10^{4} \mathrm{~Gy} / \mathrm{h}$ and a dose of $10^{7} \mathrm{~Gy}$. At a similar total dose of $1.1 \times 10^{7} \mathrm{~Gy}$ obtained at a lower radiation intensity of $4 \mathrm{kGy} / \mathrm{h}$, no bubbles were observed [42]. Appearance of oxygen bubbles was not observed at higher total doses of $\gamma$-radiation [17]. This difference was due to the fact that too high irradiation intensities were used in experiments [41] with oxygen bubbles noted being an artifact caused by a methodological error-a fundamental discrepancy between the experimental conditions and the process in HLW glass forms under study. As in the case of $\beta$-irradiation, the presence of multivalent cations of transition metals in the glass diminishes the effect of defect generation. It was noted that the effect of $\gamma$-radiation on borosilicate glasses properties is poorly studied. According to known publications, the total dose of $\gamma$-radiation in experiments with borosilicate glasses did not exceed $0.85 \times 10^{9} \mathrm{~Gy}$, while the total dose received by the glass in storage for $10^{4}$ years is $2 \times 10^{9} \mathrm{~Gy}$. In all tests with glasses of real composition, no noticeable structural changes were observed after $\gamma$-irradiation. Only limited macroscopic effects were noticed with density changes lower than 0.5 rel.\%.

\section{Effect of Neutron Radiation}

Irradiation of glasses in research reactors is done using the ${ }^{10} \mathrm{~B}(\alpha, n){ }^{7} \mathrm{Li}$ reaction which enables the generation of very high helium contents in glasses reaching around 0.5 at.\% in several months of irradiation due to $\alpha$-particles and ${ }^{7} \mathrm{Li}$ of energy of 0.84 and $1.47 \mathrm{MeV}$, respectively [6]. Since the bulk intensity of the $(\alpha, \mathrm{n})$ reactions in vitrified HLW is small, the question of effect of neutron irradiation on the properties of borosilicate glasses is of secondary interest. Changes in properties of borosilicate glasses after irradiation with a neutron flux of density up to $2.5 \times 10^{18} \mathrm{n} / \mathrm{cm}^{2}$ at flux $2 \times 10^{13}$ $n / \mathrm{cm}^{2}$ s were studied [43]. The compositions of the glasses are given in Table 4 .

A moderate change in the density can be noted (about 2 rel.\%), both positive and negative (Figure 6).

No phase separation was observed, and all types of the glasses after irradiation with neutrons remained uniform. The neutron radiation density range studied is quite enough for analysing the effect of a neutron source such as the reaction $(\alpha, n)$ on the glass properties. Therefore, the results obtained in [43] allow us to conclude that the real dose of neutron irradiation has a negligible effect on properties of nuclear waste borosilicate glasses.

\section{Effect of Radiation on Leaching}

From a practical point of view, one of the most important characteristics of any waste form is its durability, indicating on time frame during which the matrix can retain the radionuclides [5]. This parameter is determined by chemical stability of the matrix during its interaction with
TABLE 4: Compositions of borosilicate glasses subjected to neutron irradiation.

\begin{tabular}{lcccc}
\hline Oxide, wt.\% & Borofloat & $\mathrm{N}-\mathrm{ZK} 7$ & $\mathrm{~N}-\mathrm{BK} 7$ & SBSL7 \\
\hline $\mathrm{SiO}_{2}$ & 82 & 66 & 73 & 73.5 \\
$\mathrm{~B}_{2} \mathrm{O}_{3}$ & 12 & 11.5 & 10 & 9.5 \\
$\mathrm{ZnO}$ & - & 10 & - & - \\
$\mathrm{Al}_{2} \mathrm{O}_{3}$ & 1.5 & 4 & 0.25 & - \\
$\mathrm{MgO}$ & - & - & 1.25 & - \\
$\mathrm{Na}$ & 4 & 7.5 & 10 & 10 \\
$\mathrm{~K}_{2} \mathrm{O}$ & 0.5 & - & 5 & 5.5 \\
$\mathrm{CaO}$ & - & 1 & 0.25 & - \\
$\mathrm{BaO}$ & - & - & 0.25 & 0.5 \\
Density $\left(\mathrm{g} / \mathrm{cm}^{3}\right)$ & 2.2 & 2.47 & 2.491 & 2.50 \\
\hline
\end{tabular}

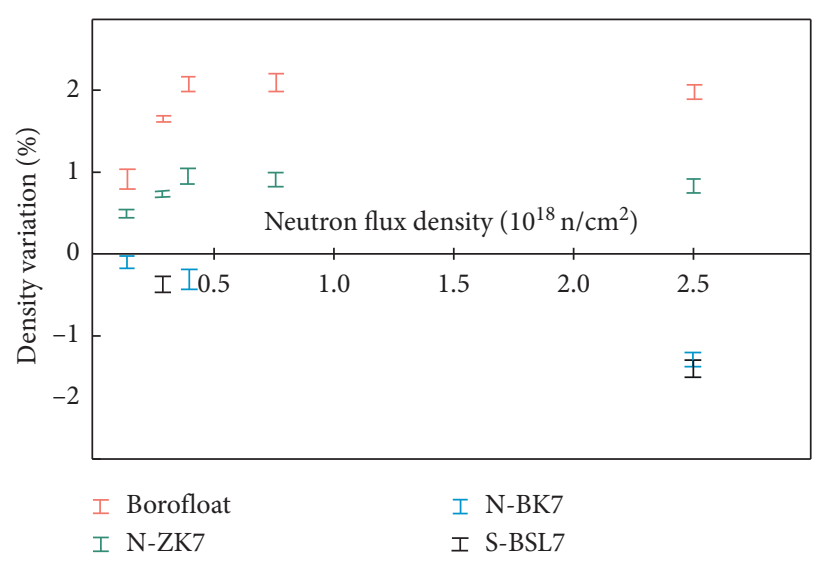

Figure 6: Dynamics of density changes in borosilicate glasses during bombardment by a neutron flux according to Boffy et al. [43]. The neutron flux is $2 \times 10^{13} \mathrm{n} /\left(\mathrm{cm}^{2} \cdot \mathrm{s}\right)$. The glass compositions are shown in Table 4.

groundwater. The irradiation influences on the stability of the matrix have two factors: (1) a change in the structure and properties of the matrix under radiation and (2) radiogenic effects at the water-matrix interface, in particular, change in characteristics of groundwater due to its radiolysis (decrease in $\mathrm{pH}$ and so on).

The authors in $[5,20,44]$ have analysed the effect of selfirradiation on two corrosion mechanisms of nuclear waste glasses: (1) diffusion-controlled ion exchange and (2) hydrolysis. The data obtained demonstrate that the ion-exchange stage of corrosion is among those that is most affected by self-irradiation. It was shown that rates of alkali ion exchange had a non-Arrhenius behavior depending both on total irradiation dose and dose rate and because of that some effects cannot be simulated by external irradiation and require in situ measurements $[5,20]$. At low temperatures of leaching, the concentration of radiation-induced defects significantly exceeds that created by thermal fluctuations; thus, radiation-induced effects are detectable, while at higher temperatures, there are no effects due to irradiation because of the high concentration of thermally induced defects. In addition, annealing of defects occurs at high temperatures $[5,20]$. Increases in dissolution rates up to 4 -fold were noted in the leaching of preirradiated glasses at doses close to $10^{9}$ Gy [45]. 
Experiments carried out with $\gamma$-irradiated glasses at high glass surface to solution volume ratio showed that $\gamma$-radiation favored the incongruent dissolution of glass [46]. Highly incongruent glass dissolution was observed in $\gamma$-irradiated in situ tests of waste glasses in Belgium Boom Clay; moreover, the glass corrosion mechanism becomes a more diffusion-controlled process in the presence of the radiation field [47]. Leach tests of French SON68 glass in silica-saturated solutions showed that ion-exchange rates are increased after irradiation, whereas hydrolysis remained unchanged [48]. Tests of radioactive glasses showed that initial leaching rates are significantly higher for radioactive samples compared to nonradioactive simulants although the long-term hydrolytic stage was unaffected [49]. Summarizing the data available $[2,5,20,42,44]$ led to the conclusion that, in cases when corrosion occurs via diffusion-controlled ion exchange, the irradiation has a detectable and significant impact. This occurs at relatively low temperatures $\left(\leq 50^{\circ} \mathrm{C}\right)$, low and medium $\mathrm{pH}(\leq 8)$, relatively high absorbed doses $\left(>6 \cdot 10^{6} \mathrm{~Gy}\right)$, and for diluted solutions at initial stages of corrosion. The most important consequences of irradiation effect in these cases are as follows: (i) enhanced leaching rates and (ii) incongruent leaching (dissolution) at glass corrosion. On contrast, when hydrolysis takes control of glass corrosion as a dominant mechanism, then practically, no differences were found in corrosion behavior of nonirradiated and irradiated glasses. These conditions prevail at temperatures $>50^{\circ} \mathrm{C}$ and high $\mathrm{pH}$ of contacting water $(>9)$ as well as at late stages of corrosion when, due to cationic depletion of near-surface glass layers, ion-exchange reactions are reduced.

In previous sections, it was noted that the radiogenic structural changes in borosilicate glasses are relatively small. However, local disordering and an increase in the density of fracturing can lead to an increase in leaching rate of glasses irradiated. The effect of $\alpha$-irradiation on leaching rate of borosilicate glasses at $20^{\circ} \mathrm{C}$ was investigated by addition of ${ }^{238} \mathrm{PuO}_{2}$ with a relative short (87.7 years) half-life $[4,17,50]$. Dynamics of changes in the leaching rate of UK189 borosilicate glass was analysed as a function of storage time of HLW (Table 5).

Table 7 presents data on leaching rates after $\alpha$-irradiation for glasses with $2.5 \mathrm{wt} . \%{ }^{238} \mathrm{PuO}_{2}$. Irradiated glass was tested for leaching after a total dose of $1.1 \times 10^{18} \alpha$-decays/g [51].

The $\alpha$-irradiation increases leaching rate at different temperatures by no more than 3 times. This conclusion is consistent with recent data [53], where glass bombarded with ${ }^{197} \mathrm{Au}$ ions to simulate displacements from recoil nuclei was studied. The dissolution rate for the irradiated glasses in these tests increased by $3.7 \pm 0.5$ times which is assumed proportional to the rate of motion of leaching front. It should be noted that the energy of gold ions is 945.6 MeV [53], while the energy of the recoil nuclei is close to $100 \mathrm{keV}$. Hence, in these experiments, the energy of particles initiating displacement cascades was overestimated by almost 10,000 times in comparison with actual conditions of $\alpha$-decay in vitrified HLW. However, even in this case, the leaching rate increased by no more than 3-4 times.
Previously presented experimental data on effect of $\beta$-radiation on properties of borosilicate glasses, as in the case of $\alpha$-radiation, indicate only insignificant structural changes in glasses at total doses and dose rates of $\beta$-radiation typical of vitrified HLW. However, even minor structural changes such as appearance of local inhomogeneities and formation of oxygen bubbles can lead to an increase in leaching rates of irradiated glasses upon their contact with groundwater. Data on effect of $\beta$-radiation on leaching rates of two types of borosilicate glasses are given in Table 8 .

Glasses were bombarded for 10 days with electrons with energy of $0.5 \mathrm{MeV}$, and the total surface irradiation dose was $10^{19}$ electrons $/ \mathrm{cm}^{2}$, which was estimated to be equivalent to $3 \times 10^{9}$ Gy [51]. At a dose of $\beta$-radiation corresponding to $10^{4}$ years of storage of HLW, the leaching rate increases by no more than 2 times.

The dependence of leaching rate of glasses on temperature described by the Arrhenius formula is as follows:

$$
J=J_{0} \exp \left(-\frac{E_{\alpha}}{\mathrm{RT}}\right)
$$

where $J$ is the leaching rate, Jo is a coefficient, $T$ is the absolute temperature, $E_{\mathrm{a}}$ is the activation energy, and $R$ is the universal gas constant. The activation energy in this case determines how much the leaching rate changes with temperature.

Experimental data indicate that $\alpha$-irradiation which is not noticeable affects the activation energy of glass leaching reaction (Figure 7).

When studying the effect of irradiation on durability of glasses in contact with groundwater, it is necessary to bear in mind not only the effect of radiation on properties of glasses but also the radiolysis of contacting water. Both $\alpha$ - and $\beta$-radiation originated from the vitrified HLW penetrate the liquid to a relatively small depth. In this regard, insignificant volumes of liquid are exposed to radiation and hence to alteration due to radiolysis. This will restrict a degree of influence of radiolysis on leaching in the case of $\alpha$ - and $\beta$-radiation. The penetration depth of gamma-radiation into the liquid is much greater. Accordingly, the volume of liquid in which radiolysis can take place is also larger. Therefore, it can be expected that, in the case of $\gamma$-radiation, the effect of radiolysis on glass leaching will be significant. A study of the effect of $\gamma$-radiation on the leaching of borosilicate glasses taking account of radiolysis was carried out in [54] on the PNL 76-68 glass. Its composition is in wt.\%: $\mathrm{SiO}_{2}$ (39.80), $\mathrm{B}_{2} \mathrm{O}_{3}$ (9.47), $\mathrm{P}_{2} \mathrm{O}_{5}$ (0.48), $\mathrm{Na}_{2} \mathrm{O}$ (12.51), $\mathrm{Fe}_{2} \mathrm{O}_{3}$ (9.77), $\mathrm{TiO}_{2}$ (2.97), $\mathrm{CaO}$ (2), and 23 wt.\% of modifiers and components of HLW. Samples were immersed in deionized water; the ratio of the sample surface area to the water volume was $0.1 \mathrm{~cm}^{-1}$, and $\gamma$-irradiation was carried out by a ${ }^{60} \mathrm{Co}$ source with a dose rate of $2.4 \times 10^{4} \mathrm{~Gy} / \mathrm{h}$. A comparison of data (Table 9) on nonirradiated $(a)$ and irradiated preleaching $(b)$ samples shows the role of $\gamma$-irradiation of $\mathrm{B}$-Si glasses on their leaching without water radiolysis.

Only a slight increase ( $<20$ rel.\%) in the contents of various glass components in solution after leaching can be noted. A significantly different result is obtained from a comparison of experiments on samples $a$ and $c$ (leaching was 
TABLe 5: Dynamics of UK189 glass leaching with ${ }^{238} \mathrm{PuO}_{2}$ additive as source of $\alpha$-radiation [51, 52].

\begin{tabular}{lcc}
\hline Total dose, $\alpha / \mathrm{g}$ & HLW storage time equivalent to dose absorbed (years) & Leaching rate $\left(\mathrm{mg} /\left(\mathrm{cm}^{2} \times\right.\right.$ day $\left.)\right)$ \\
\hline $0.89 \times 10^{18}$ & 7000 & 1.6 \\
$2.0 \times 10^{18}$ & 250000 & 2.3 \\
$2.7 \times 10^{18}$ & 500000 & 2.3 \\
$3.3 \times 10^{18}$ & 700000 & 2.3 \\
$5.5 \times 10^{18}$ & 1400000 & 3.2 \\
\hline
\end{tabular}

The leaching rate of unirradiated UK 189 glass (Table 6) was $1.3 \pm 0.2 \mathrm{mg} / \mathrm{cm}^{2}$ day.

TABLE 6: The composition of borosilicate glasses, produced in UK, wt.\% [52].

\begin{tabular}{lcc}
\hline Oxide & UK 189 & UK 209 \\
\hline $\mathrm{SiO}_{2}$ & 41.51 & 50.88 \\
$\mathrm{~B}_{2} \mathrm{O}_{3}$ & 21.87 & 11.12 \\
$\mathrm{Na}_{2} \mathrm{O}$ & 7.68 & 8.30 \\
$\mathrm{Li}{ }_{2} \mathrm{O}$ & 3.69 & 3.99 \\
$\mathrm{MgO}$ & 6.23 & 6.34 \\
$\mathrm{Al}_{2} \mathrm{O}_{3}$ & 5.03 & 5.11 \\
$\mathrm{Fe}_{2} \mathrm{O}_{3}$ & 2.68 & 2.73 \\
$\mathrm{Cr}_{2} \mathrm{O}_{3}$ & 0.55 & 0.56 \\
$\mathrm{NiO}$ & 0.36 & 0.36 \\
$\mathrm{ZnO}$ & 0.44 & 0.44 \\
$\mathrm{U}_{3} \mathrm{O}_{8}$ & 0.06 & 0.06 \\
\hline
\end{tabular}

TABLE 7: Changes in leaching rate of glasses caused by $\alpha$-irradiation at a dose of $1.1 \times 10^{18} \alpha$-decays/g.

\begin{tabular}{lccc}
\hline Glass & Temperature $\left({ }^{\circ} \mathrm{C}\right)$ & \multicolumn{2}{c}{ Leaching rate $\left(\mathrm{mg} / \mathrm{cm}^{2} \times\right.$ day) } \\
& & Nonirradiated glass & 1.33 \\
Irradiated glass \\
\hline UK 189 & 20 & 1.09 & 1.91 \\
UK 189 & 170 & 0.21 & 0.23 \\
UK 209 & 20 & 0.23 & 0.28 \\
UK 209 & 170 & 2.26 & 6.9 \\
SON 58.30.20.U2 & 20 & 2.19 & 2.33 \\
SON 58.30.20.U2 & 170 & & \\
\hline
\end{tabular}

TABLE 8: Effect of $\beta$-irradiation equivalent to $3 \times 10^{9} \mathrm{~Gy}$ on leaching rates of borosilicate glasses [50].

\begin{tabular}{lccc}
\hline Temperature $\left({ }^{\circ} \mathrm{C}\right)$ & Glass & \multicolumn{2}{c}{ Leaching rate $\left(\mathrm{mg} / \mathrm{cm}^{2} \times\right.$ day $\left.)\right)$} \\
& & Nonirradiated & Irradiated \\
\hline $25-50$ & UK 189 & 1.3 & 2.5 \\
$125-150$ & UK 210 & 1.4 & 1.9 \\
\hline
\end{tabular}

carried out simultaneously with irradiation, but without contact of the leach solution with air). In this case, upon irradiation, the concentrations of individual elements in the solution increased by 4-5 times and the $\mathrm{Zn}$ concentration by more than an order of magnitude. It is notable that, in experiments with samples $a$ and $b, \mathrm{pH}$ values of solution slightly increased from 5.7 to 7.2 during the experiment. In the test with sample $c$, the increase in $\mathrm{pH}$ was somewhat smaller. A comparison of results of experiments on samples $a$ and $d$ (this sample was irradiated during leaching, and the leaching solution was in contact with air) allows us to note an even greater contrast in concentrations of elements in the solution. Barium concentration, for example, increased by almost an order of magnitude. During the experiment on sample $d$, the $\mathrm{pH}$ value decreased from 5.7 to 3.3.
Thus, experiments in [54] unambiguously indicate that the effect of $\gamma$-radiation on leaching rates of borosilicate glasses is relatively weak due to structural changes in glass under action of radiation and much stronger due to radiolysis of leaching solution. Moreover, this effect is most significant in the case when the solution is in contact with air. The intensification of leaching in this case can be explained as follows. Under radiolysis of water, the concentration of complex ions containing oxygen and hydrogen increases. Nitrogen enters water from the air (the concentration of nitrogen dissolved in water is determined by Henry's law) and is oxidized by oxygen ions, which leads to formation of nitric acid accelerated leaching. This conclusion is supported by the decrease in $\mathrm{pH}$ during the run on sample $d$. A comparison of results on samples $e$ and $f$ shows 


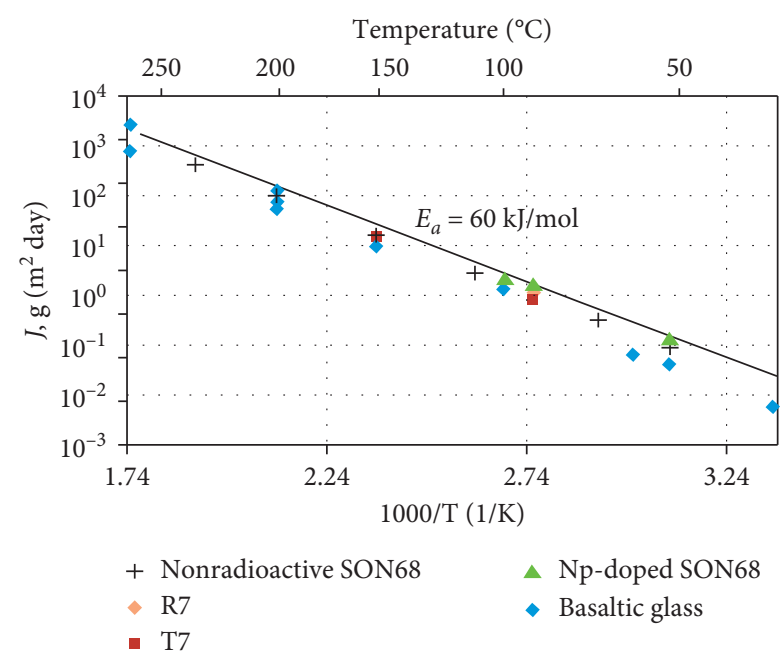

FIGURE 7: Temperature dependence of leaching rate of $\alpha$-irradiated and nonirradiated glasses [6].

TABLE 9: Effect of $\gamma$-irradiation on leaching rate of glass PNL 76-68 with account for radiolysis [54].

\begin{tabular}{|c|c|c|c|c|c|c|}
\hline Sample & $a$ & $b$ & $c$ & $d$ & $e$ & $f$ \\
\hline$T\left({ }^{\circ} \mathrm{C}\right)$ & 50 & 50 & 50 & 50 & 90 & 90 \\
\hline Time of leaching, days & 5 & 5 & 5 & 5 & 13 & 13 \\
\hline Contact with air & No & No & No & + & No & + \\
\hline Irradiation before leaching & No & + & No & No & No & No \\
\hline Irradiation during the leaching & No & No & + & + & No & + \\
\hline \multicolumn{7}{|c|}{ Content of elements in water solution after leaching, $10^{-4}$ wt.\% } \\
\hline $\mathrm{Na}$ & 0.82 & 0.96 & 4.7 & 5.0 & 18.5 & 130.0 \\
\hline Cs & 0.1 & 0.1 & 0.18 & 0.4 & 2.2 & 9.1 \\
\hline $\mathrm{Ca}$ & 0.11 & 0.13 & 0.41 & 0.8 & 1.0 & 7.8 \\
\hline $\mathrm{Ba}$ & 0.02 & 0.03 & 0.07 & 0.19 & 0.1 & 0.8 \\
\hline $\mathrm{Sr}$ & 0.02 & 0.03 & 0.07 & 0.14 & 0.2 & 1.4 \\
\hline $\mathrm{Si}$ & 1.6 & 1.9 & 5.5 & 6.5 & 21.0 & 177.1 \\
\hline B & 0.26 & 0.29 & 0.85 & 1.1 & 4.5 & 31.3 \\
\hline Mo & 0.1 & 0.12 & 0.38 & 0.1 & 2.6 & 7.2 \\
\hline $\mathrm{Zn}$ & 0.06 & 0.07 & 0.80 & 2.0 & 0.09 & 37.6 \\
\hline $\mathrm{Nd}$ & $<0.02$ & $<0.02$ & 0.13 & & & \\
\hline $\mathrm{Ce}$ & $<0.04$ & $<0.04$ & $<0.04$ & & & \\
\hline $\mathrm{Fe}$ & $<0.005$ & $<0.005$ & 0.015 & 0.67 & $<0.05$ & 0.2 \\
\hline $\mathrm{pH}$ before/after irradiation & $5.7 / 7.2$ & $5.7 / 7.2$ & $5.7 / 6.5$ & $5.7 / 3.3$ & $5.7 / 8.5$ & $4.7 / 4.6$ \\
\hline
\end{tabular}

that this effect intensifies with rise of temperature. It should be borne in mind that the maximum dose of $\gamma$-radiation in experiments [54] did not exceed $7.5 \times 10^{6} \mathrm{~Gy}$, whereas, according to estimates, the $\gamma$-radiation dose of vitrified HLW in storage for $10^{4}$ years is equal to $2 \times 10^{9} \mathrm{~Gy}$. It can be expected that, at these doses, the effect of $\gamma$-radiation on durability of borosilicate glasses due to radiolysis of water will be even more significant.

\section{Phosphate Glasses}

Fewer data are published on effects of irradiation on properties of aluminum-phosphate glasses. This is mainly due to the fact that such glasses are industrially used as HLW matrix only in Russia, and they are not of practical interest for other countries. It was shown that, under the influence of electron irradiation even at low doses $\left(0.8 \times 10^{23}\right.$ electrons/ $\mathrm{m}^{2}$ ), gas bubbles formed [55]. As the absorbed dose increases, the size of bubbles grows, and they move from the inner parts to the glass surface. At a dose of $2.2 \times 10^{26}$ electrons $/ \mathrm{m}^{2}\left(6.6 \times 10^{11} \mathrm{~Gy}\right)$, all bubbles are removed out of glass. With further exposure of glass to a dose of $4.5 \times 10^{26}$ electrons $/ \mathrm{m}^{2}$, areas enriched in $\mathrm{Al}$ and $\mathrm{P}$ are formed.

We have performed investigation on simulant nuclear waste sodium-aluminum-phosphate (NAP) glass irradiated at RHM- $\gamma-20$ irradiator (based on ${ }^{60} \mathrm{Co}$ source) of FSUE "RADON with a dose of $62 \times 10^{6} \mathrm{~Gy}$. The composition of NAP glass was as follows (wt.\%): $\mathrm{Na}_{2} \mathrm{O}, 22.3 ; \mathrm{Al}_{2} \mathrm{O}_{3}, 9.2$; $\mathrm{Fe}_{2} \mathrm{O}_{3}, 15.6 ; \mathrm{P}_{2} \mathrm{O}_{5}, 52.1$. The normalized leaching rates were determined using the state test protocol [56] which is analogue of the ASTM test procedure [57]. The normalized leaching rate $J_{E l}(t)$ for the same glass elements runs approximately parallel to each other for both nonirradiated and irradiated glasses (Figure 8). 


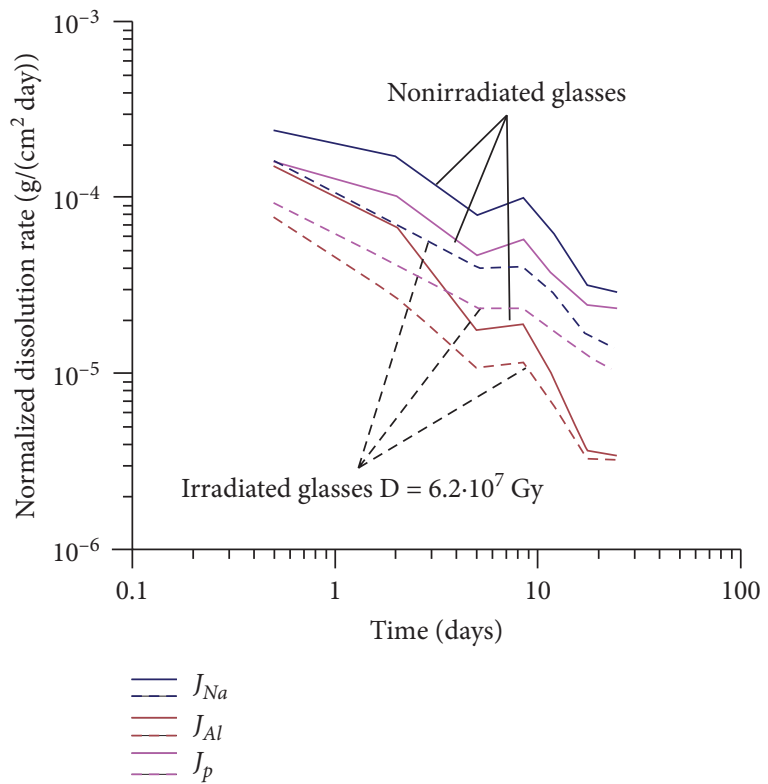

Figure 8: Effect of irradiation on elements with normalized leaching rates from the NAP glass at $90^{\circ} \mathrm{C}$.

TABLE 10: Ratios of leaching rates $J_{E l}(t)$ of nonirradiated and irradiated NAP glasses.

\begin{tabular}{lc}
\hline Element & Ratio after 12 days \\
\hline $\mathrm{Al}$ & 1.44 \\
$\mathrm{Na}$ & 2.22 \\
$\mathrm{P}$ & 2.08 \\
\hline
\end{tabular}

This suggests that, over the whole-time range, the ratio $J_{E l}(t)$ obtained for the initial and irradiated glasses remains almost the same. The ratios of values of $J_{E l}(t)$ after 12 days of leaching are shown in Table 10.

More information on this investigation can be found in [58]. Thus, as a result of $\gamma$-irradiation, the leaching rate of the NAP glass has averagely decreased by about 2 times. This effect is probably explained by radiation-induced annealing that occurs in the other types of glasses $[5,20]$.

\section{Conclusions}

From analysis of existing data, it can be concluded that $\alpha$-irradiation and $\beta$-irradiation have a weak effect on structure of borosilicate HLW glasses at irradiation doses corresponding to the storage/disposal time of vitrified HLW. This effect is manifested in a slight change in density of glasses by no more than a few percent, formation of oxygen-helium bubbles in glass with dimensions of $1 \mu \mathrm{m}$ and less, and a local disordering of the glass structure. Structural changes lead to an increase in leaching rate of nuclear waste borosilicate glasses in water by no more than 2-4 times in the presence of radiation. The effect of water radiolysis due to $\alpha$-irradiation and $\beta$-irradiation on leaching of nuclear waste borosilicate glasses can be notable. Process of $\gamma$-irradiation affects structure of borosilicate and phosphate glasses in similar way as $\beta$-radiation. Effect of $\gamma$-irradiation on the glass structure is insignificant and includes an increase in structural disorder, formation of oxygen microbubbles, and a slight change in density. The role of these structural changes for glass leaching is relatively small. A much greater effect on leaching of borosilicate glasses is exerted by radiolysis of water, which is more significant with $\gamma$-irradiation than with $\beta$-irradiation. Within the doses up to $10^{7}$ Gray, radiolysis due to $\gamma$ radiation increased the leaching rate of elements of borosilicate glasses by an order of magnitude. However, this is unlikely to occur in the disposal environment where the water is expected to contact the glass after corrosion of container in thousands of years when the intensity of radiation will be diminished. Research of Na-Al-Fe-P glass reveals that irradiation with a dose of $6.2 \times 10^{7}$ Gy decreased the leaching rates of elements approximately 2 times due to radiationinduced annealing of the glasses structure.

\section{Data Availability}

Data used to support findings of this study can be made available from the corresponding author upon request.

\section{Conflicts of Interest}

The authors declare that there are no conflicts of interest regarding the publication of this paper.

\section{Acknowledgments}

The study was funded by the Federal Budget within the framework of the State Tasks of Scientific Investigations for the IGEM RAS. The authors thank O.I. Stefanovsky for synthesis of the Na-Al-P glass, E.E. Ostashkina for its gamma irradiation, and S.S. Danilov for investigation of the leaching behaviour of the specimen.

\section{References}

[1] J. R. Phillips, A. Korinny, F. Depisch, and Z. Drace, "Update of the INPRO methodology in the area of waste management," Sustainability, vol. 10, no. 970, p. 9, 2018.

[2] M. I. Ojovan, W. E. Lee, and S. N. Kalmykov, "3rd edition," An Introduction to Nuclear Waste Immobilisation, p. 497, Elsevier, Amsterdam, Netherlands, 2019.

[3] N. C. Hyatt and M. I. Ojovan, "Special issue: materials for nuclear waste immobilization," Materials, vol. 12, no. 21, p. 4, 2019.

[4] S. Gin, P. Jollivet, M. Tribet, S. Peuget, and S. Schuller, "Radionuclides containment in nuclear glasses: an overview," Radiochimica Acta, vol. 105, pp. 927-959, 2017.

[5] M. I. Ojovan and W. E. Lee, New Developments in Glassy Nuclear Wasteforms, p. 131, Nova, New York, NY, USA, 2007.

[6] S. Gin, I. Ribet, S. Peuget, and J.-M. Delaye, "Long-term behavior of glasses," in Nuclear Waste Conditioning, J.-F. Pansot, Ed., pp. 51-64, CEA, Paris, France, 2009.

[7] W. Lutze, "Silicate glasses," in Radioactive Waste Forms for the Future, W. Lutze and R. Ewing, Eds., pp. 1-160, Elsevier Science Publishers B.V., Amsterdam, Netherlands, 1988. 
[8] H. Wiese and M. Demonie, "Operation of the Pamela highlevel waste vitrification facility," Nuclear Engineering and Design, vol. 137, no. 1, pp. 147-151, 1992.

[9] N. P. Laverov, B. I. Omelyanenko, and S. V. Yudintsev, "Mineralogy and geochemistry of preserving matrices of highly active waste," Geology of Ore Deposits, vol. 39, no. 3, pp. 211-228, 1997.

[10] J. T. Carter, A. J. Luptak, J. Gastelum, Ch. Stockman, and A. Miller, Fuel Cycle Potential Waste Inventory for Disposition, p. 328, U.S. Department of Energy, Washington, DC, USA, 2012.

[11] M. I. Ojovan, "On alteration rate renewal stage of nuclear waste glass corrosion," MRS Advances, vol. 5, no. 3-4, pp. 111-120, 2020.

[12] C. M. Jantzen and M. I. Ojovan, "On selection of matrix (wasteform) material for higher activity nuclear waste immobilization (Review)," Russian Journal of Inorganic Chemistry, vol. 64, no. 13, pp. 1611-1624, 2019.

[13] A. A. Vashman, A. V. Demine, N. V. Krylova et al., Phosphate Glasses with Radioactive Waste, p. 172, CNIIatominform, Moscow, Russia, 1997.

[14] I. W. Donald, Waste Immobilisation in Glass and Ceramic Based Hosts, p. 507, Wiley, Chichester, UK, 2010.

[15] A. Goel, J. S. McCloy, R. Pokorny, and A. A. Kruger, "Challenges with vitrification of Hanford High-Level Waste (HLW) to borosilicate glass-an overview," Journal of Noncrystalline Solids: X, vol. 4, Article ID 100033, 2019.

[16] C. P. Kaushik, "Indian program for vitrification of high level radioactive liquid waste," Procedia Materials Science, vol. 7, no. 16-22, 2014.

[17] W. J. Weber, R. C. Ewing, C. A. Angel et al., "Radiation effects in glass used for immobilization of high-level waste and plutonium disposition," Journal of Materials Research and Technology, vol. 12, no. 8, pp. 1946-1978, 1997.

[18] D. J. Wronkiewicz, "Radionuclide decay effects on waste glass corrosion," MRS Proceedings, vol. 333, pp. 83-97, 1993.

[19] P. Van Iseghem, "Glass in its disposal environment. Proc. Int. Topical workshop on glass in its disposal environment," Journal of Nuclear Materials, vol. 298, no. 1-2, 2001.

[20] M. I. Ojovan and W. E. Lee, "Alkali ion exchange in $\gamma$-irradiated glasses," Journal of Nuclear Materials, vol. 335, no. 3, pp. 425-432, 2004.

[21] A. V. Zotov, K. A. Levin, L. O. Magazin et al., "Interaction of aluminophosphate glass with water at elevated temperatures," Geochemistry, vol. 9, pp. 891-904, 1996.

[22] V. I. Malkovsky, S. V. Yudintsev, and E. V. Aleksandrova, "Influence of Na-Al-Fe-P glass alteration in hot non-saturated vapor on leaching of vitrified radioactive wastes in water," Journal of Nuclear Materials, vol. 508, pp. 212-218, 2018.

[23] J. Neeway, A. Abdelouas, B. Grambow et al., "Vapor hydration of SON68 glass from $90^{\circ} \mathrm{C}$ to $200^{\circ} \mathrm{C}$ : a kinetic study and corrosion products investigation," Journal of Non-crystalline Solids, vol. 358, no. 21, pp. 2894-2905, 2012.

[24] R. F. Bartholomew, P. A. Tick, and S. D. Stookey, "Water/glass reactions at elevated temperatures and pressures," Journal of Non-crystalline Solids, vol. 38-39, pp. 637-642, 1980.

[25] B. E. Burakov, M. I. Ojovan, and W. E. Lee, Crystalline Materials for Actinide Immobilisation, p. 198, Imperial College Press, London, UK, 2010.

[26] B. Y. Zubekhina, A. A. Shiryaev, B. E. Burakov et al., "Chemical alteration of 238Pu-loaded borosilicate glass under saturated leaching conditions," Radiochimica Acta, vol. 108, no. 1, pp. 19-27, 2020.
[27] C. M. Jantzen, D. I. Kaplan, N. E. Bibler, D. K. Peeler, and M. John Plodinec, "Performance of a buried radioactive high level waste (HLW) glass after 24 years," Journal of Nuclear Materials, vol. 378, no. 3, pp. 244-256, 2008.

[28] M. I. Ojovan, W. E. Lee, A. S. Barinov et al., "Corrosion of low level vitrified radioactive waste in a loamy soil," Glass Technology, vol. 47, pp. 48-55, 2006.

[29] N. E. Bibler, "Effects of alpha, gamma, and alpha-recoil radiation on borosilicate glass containing Savannah River Plant defense high-level nuclear waste," MRS Proceedings, vol. 6, pp. 681-689, 1981.

[30] K. Trachenko, M. T. Dove, E. Artacho, I. T. Todorov, and W. Smith, "Atomistic simulations of resistance to amorphization by radiation damage," Physical Review B, vol. 73, p. 174207, 2006.

[31] S. X. Wang, L. M. Wang, R. C. Ewing, and R. H. Doremus, "Ion beam-induced amorphization in MgO-Al2O3-SiO2. I. Experimental and theoretical basis," Journal of Non-crystalline Solids, vol. 238, no. 3, pp. 198-213, 1998.

[32] D. A. Kilymis and J. M. Delaye, "Deformation mechanisms during nanoindentation of sodium borosilicate glasses of nuclear interest," Journal of Chemical Physics, vol. 141, Article ID 014504, 2014.

[33] W. J. Weber, "Radiation and thermal ageing of nuclear waste glass," Procedia Materials Science, vol. 7, pp. 237-246, 2014.

[34] S. Peuget, J.-M. Delaye, and C. Jégou, "Specific outcomes of the research on the radiation stability of the French nuclear glass towards alpha decay accumulation," Journal of Nuclear Materials, vol. 444, no. 1-3, pp. 76-91, 2014.

[35] Y. Inagaki, H. Furuya, K. Idemitsu, T. Banda, S. Matsumoto, and S. Muraoka, "Microstructure of simulated high-level waste glass doped with short-lived actinides, $238 \mathrm{Pu}$ and 244Cm," MRS Proceedings, vol. 257, pp. 199-206, 1991.

[36] G. Gutierrez, S. Peuget, J. A. Hinks et al., "Helium bubble formation in nuclear glass by in-situ TEM ion implantation," Journal of Nuclear Materials, vol. 452, no. 1-3, pp. 565-568, 2014.

[37] A. H. Mir, S. Peuget, M. Toulemonde et al., "Defect recovery and damage reduction in borosilicate glasses under double ion beam irradiation," EPL (Europhysics Letters), vol. 112, no. 3, p. $36002,2015$.

[38] C. L. Dube, M. C. Stennett, A. S. Gandy, and N. C. Hyatt, "Simulation of alpha decay of actinides in iron phosphate glasses by ion irradiation," Nuclear Instruments and Methods in Physics Research Section B: Beam Interactions with Materials and Atoms, vol. 371, pp. 424-428, 2016.

[39] G. Moebus, M. Ojovan, S. Cook, J. Tsai, and G. Yang, "Nanoscale quasi-melting of alkali-borosilicate glasses under electron irradiation," Journal of Nuclear Materials, vol. 396, p. 264, 2010.

[40] Y. X. Wang, F. Ohuchi, and P. H. Holloway, "Mechanisms of electron stimulated desorption from soda-silica glass surfaces," Journal of Vacuum Science \& Technology A: Vacuum, Surfaces, and Films, vol. 2, no. 2, pp. 732-737, 1984.

[41] D. G. Howitt, H. W. Chan, J. F. DeNatale, and J. P. Heuer, "Mechanism for the radiolytically induced decomposition of soda-silicate glasses," Journal of the American Ceramic Society, vol. 74, no. 5, pp. 1145-1147, 1991.

[42] A. S. Pankov, O. G. Batyukhnova, M. I. Ojovan, and W. E. Lee, "Simulation of self-irradiation of high-sodium content nuclear waste glasses," MRS Proceedings, vol. 985, p. 6, 2007.

[43] R. Boffy, S. Peuget, R. Schweins, J. Beaucour, and F. J. Bermejo, "High thermal neutron flux effects on structural and macroscopic properties of alkali-borosilicate glasses used 
as neutron guide substrate," Nuclear Instruments and Methods in Physics Research Section B: Beam Interactions with Materials and Atoms, vol. 374, pp. 14-19, 2016.

[44] M. I. Ojovan and W. E. Lee, "Role of self-irradiation in corrosion of nuclear waste glasses," in Proceedings of the WM'06 Conference, p. 13p, Tucson, Arizona, February-March 2006.

[45] N. E. Bibler and J. A. Kelley, Savannah River Laboratory Report DP-1482, S.C. Savannah River Lab, Department of Energy, Aiken, SC, USA, 1978.

[46] K. Lemmens and P. Van Iseghem, "The effect of gamma radiation on the dissolution of high-level waste glass in Boom clay," MRS Proceedings, vol. 663, pp. 175-182, 2001.

[47] P. Van Iseghem, E. Valcke, and A. Lodding, "In situ testing of the chemical durability of vitrified high-level waste in a Boom Clay formation in Belgium: discussion of recent data and concept of a new test," Journal of Nuclear Materials, vol. 298, no. 1-2, pp. 86-94, 2001.

[48] A. Abdelouas, K. Ferrand, B. Grambow et al., "Effect of gamma and alpha irradiation on the corrosion of the French borosilicate glass SON 68," MRS Proceedings, vol. 807, pp. 175-180, 2004.

[49] T. Advocat, P. Jollivet, J. L. Crovisier, and M. Del Nero, "Longterm alteration mechanisms in water for SON68 radioactive borosilicate glass," Journal of Nuclear Materials, vol. 298, no. 1-2, pp. 55-62, 2001.

[50] W. G. Burns, A. E. Hughes, J. A. C. Marples, R. C. Nelson, R. S. Nelson, and A. M. Stoneham, "Radiation effects and the leach rates of vitrified radioactive waste," Nature, vol. 295, no. 5845 , pp. $130-132,1982$.

[51] W. G. Burns, A. E. Hughes, J. A. C. Marples, R. C. Nelson, R. S. Nelson, and A. M. Stoneham, "Effects of radiation on the leach rates of vitrified radioactive waste," Journal of Nuclear Materials, vol. 107, no. 2-3, pp. 245-270, 1982.

[52] A. R. Hall, A. Hough, and J. A. C. Marples, "Leaching of vitrified high-level waste," Scientific Basis for Radioactive Waste Management, vol. 11, pp. 83-92, 1982.

[53] M. I. Lönartz, L. Dohmen, C. Lenting, C. Trautmann, M. Lang, and T. Geisler, "The Effect of heavy ion irradiation on the forward dissolution rate of borosilicate glasses studied in situ and real time by fluid-cell Raman spectroscopy," Materials, vol. 12, no. 1480, p. 13, 2019.

[54] G. L. McVay, W. J. Weber, and L. R. Pederson, "Effects of radiation on the leaching behavior of nuclear waste forms," Nuclear and Chemical Waste Management, vol. 2, no. 2, pp. 103-108, 1981.

[55] K. Sun, L. M. Wang, and R. C. Ewing, "Microstructure and chemistry of an aluminophosphate glass waste form under electron beam irradiation," MRS Proceedings, vol. 807, pp. 121-126, 2003.

[56] GOST R. 52126-2003," Radioactive Waste. Determination of Chemical Resistance of Solidified High-Level Waste by Continuous Leaching, p. 6, IPC Standards Publishing, Moscow, Russia, 2003.

[57] ASTM C 1220-98, Standard Test Method for Static Leaching of Monolithic Waste Forms for Disposal of Radioactive Waste, p. 16, ASTM International, West Conshohocken, PA, USA, 2004.

[58] A. V. Luzhetsky, V. A. Petrov, S. V. Yudintsev et al., "Effect of gamma irradiation on structural features and dissolution of nuclear waste Na-Al-P glasses in water," Sustainability, vol. 12, no. 10, p. 4137, 2020. 